\section{$\bullet$ \\ Morphologic Pattern of Upper Gastrointestinal Tract Lesions - Endoscopic Biopsy Analysis}

IJCRR

Section: Healthcare

ISI Impact Factor

(2019-20): 1.628

IC Value (2019): 90.81

$\operatorname{SJIF}(2020)=7.893$

\section{Rajesh Kothari ${ }^{1}$, Sanjay Agrawal' ${ }^{2}$, Vineeta Kothari ${ }^{3}$}

\author{
'Assistant Professor, Department of General Surgery, Amaltas Institute of Medical Sciences, Dewas, MP, India; ${ }^{2}$ Professor and HOD, Depart- \\ ment of ENT, Govt. Medical College, Khandwa, MP, India; ${ }^{3}$ Pathologist CEO and Lab Director, Central Lab Indore, MP, India.
}

\title{
ABSTRACT
}

Introduction: A diagnostic technique that visualizes the upper portion of the gastrointestinal tract up to the duodenum is the upper gastrointestinal endoscopy. It is a proven model of investigation and plays a crucial role in the precise detection and treatment of a wide variety of upper gastro-intestinal conditions in conjunction with biopsy.

Objectives: To study the Morphological pattern of lesions of the upper gastrointestinal tract from the endoscopic biopsies.

Methods: The present research was performed with endoscopic biopsies of the upper gastrointestinal tract over two years in the pathology department of a tertiary care hospital.

Results: In 828 patients, biopsy materials were collected from various levels of the upper gastrointestinal tract. This included 288 biopsies from the oesophagus (35\%), 84 from the gastric junction of the oesophagus (10\%), 444 from the stomach (54\%) and 12 from the small intestine (2\%). There were $280(34 \%)$ cases that were non-neoplastic, while 548 (66\%) were neoplastic. Histopathology revealed gastritis of varying grades (27\%) as the inflammatory lesion most frequently diagnosed, while the most frequently diagnosed malignant lesion was squamous cell carcinoma (37\%).

Conclusion: A strong correlation between endoscopic and histological diagnosis was shown in this research. It further indicates that the predominant site of upper gastro-intestinal malignancy is the oesophagus.

Key Words: Upper gastro-intestinal malignancy, Biopsy, Endoscopy, Histopathology

\section{INTRODUCTION}

The oesophagus, stomach and duodenum from the upper gastrointestinal tract. Symptoms of trouble swallowing, stomach discomfort, vomiting and hematemesis are usually present in patients with upper gastrointestinal system diseases. ${ }^{1,2}$ One of the most common sites for neoplasms, particularly malignant tumours, is the upper gastrointestinal tract. A diagnostic technique that visualizes the upper portion of the gastrointestinal tract up to the duodenum is the upper gastrointestinal endoscopy. ${ }^{3}$ It is a proven method of researching and treating a wide variety of upper gastrointestinal conditions. As the main form of diagnosing upper gastrointestinal disease, it has replaced upper gastro-intestinal radiography. ${ }^{4,5}$ First used in 1968, the upper gastro-intestinal flexible fibreoptic endoscope proved to be a significant advance in gastro-intestinal tract lesion diagnosis. A convenient technique and current gold standard for reliable objective evaluation of patients with upper gastrointestinal tract symptoms is endoscopic biopsy accompanied by histopathological review. ${ }^{6}$ It is used not only to diagnose malignant \& inflammatory lesions, but also to track the path, nature of the disease, therapy response, and early complication detection. This is reflected by a growing trend in the upper gastrointestinal tract to receive mucosal biopsies. ${ }^{78}$ Endoscopic screening can detect gastric mucosal lesions at an early stage particularly atrophy, intestinal metaplasia and dysplasia to prevent the progress of lesions to invasive cancer. ${ }^{9,10}$ Oesophageal $\&$ gastric cancers are the most prevalent cancers found in men, according to the National Cancer Registry, while oesophageal cancer ranks third among women after breast and cervix carcinoma. ${ }^{11}$

\section{MATERIALS AND METHODS}

The present research was performed for two years in the Department of Pathology. We obtained a total of 828 biopsy

\section{Corresponding Author:}

Dr. Rajesh Kothari, Assistant Professor, Department of General Surgery, Amaltas Institute of Medical Sciences, Dewas, MP, India.

ISSN: 2231-2196 (Print)

Received: 09.09 .2020
ISSN: 0975-5241 (Online)

Revised: 14.10 .2020
Accepted: 06.12 .2020
Published: 03.03 .2021 
materials from different levels of the upper gastrointestinal tract during this two year study period. A flexible fibre-optic upper gastrointestinal endoscope was used to obtain the biopsy materials. Endoscopic tests and biopsies were carried out in patients of both sexes over 12 years of age with upper gastrointestinal symptoms. All patients involved in this study received informed consent. Using standardized proforma, relevant history and clinical information were documented. Both biopsy samples were counted for tissue fragments and immediately placed in $10 \%$ neutral formalin, accompanied by traditional processing $\&$ embedding of tissue. There were five micron thick parts cut $\&$ slides prepared. Each segment was stained and studied with Haematoxylin and Eosin stain. To observe H.Pylori, additional segments were stained with Giemsa. Wherever possible, Alcian blue stain to observe intestinal metaplasia and Periodic Acid Schiff (PAS) stain were performed. According to the WHO classification of the gastrointestinal tumour and tumour like symptoms, lesions were diagnosed.

\section{RESULTS}

Of the 828 cases ( Table 1), 540 (65\%) were men and 288 (35\%) were women with a 1.9:1 ratio of male to female. The age group of patients ranged from 15 years to 85 years in the current study and the highest number of cases were identified in the 40-60 year age group, representing a total of 40 $\%$ of the study population, followed by $60-80$ years ( $34 \%$ ), $20-40$ years $(19 \%)$ and the lowest incidences $(4 \%)$ in 10 20 years. Of the 828 endoscopic biopsies, 444 were gastric biopsies (54\%), 288 were oesophageal biopsies (35\%), 84 were oesophagus-gastric junction biopsies (10\%) and about 12 were duodenal biopsies ( $1 \%)$. There were 280 (34\%) cases that were non-neoplastic, while $548(66 \%)$ were neoplastic. $272(50 \%)$ of the 548 neoplastic cases were from the oesophagus, 192 (35\%) were from the stomach, and 84 $(15 \%)$ were from the oesophagus-gastric junction. Gastritis was found to be the most frequently diagnosed inflammatory lesion by histopathology ( $27 \%)$, while squamous cell carcinoma (37\%) was the most frequently diagnosed malignant lesion. 272 cases of the 288 oesophageal lesions were malignant. Squamous cell carcinoma has been noted in 272 oesophagus biopsies and 34 oesophagus-gastric junction biopsies. Of these cases, $33 \%$ were well-differentiated squamous cell carcinoma, $63 \%$ were moderately differentiated squamous cell carcinoma, and 5\% were poorly differentiated squamous cell carcinoma. In the stomach, two cases showed hyperplastic polyp, two cases of foreign body granuloma, \& 220 specimens with varying grades of gastritis were noted. Adenocarcinoma has been noted in 190 stomach biopsies and 50 oesophagogastric junction biopsies. Nonspecific duodenitis was demonstrated in 2 cases by endoscopic biopsies involving the upper two sections of the duodenum, villous atrophy in 2 cases and duodenal ulcer in 6 cases.

Table 1: Histopathological findings in upper GI biopsies

\begin{tabular}{|c|c|c|}
\hline LESION & $\begin{array}{l}\text { NO OF } \\
\text { CASES }\end{array}$ & $\%$ AGE $(\%)$ \\
\hline \multicolumn{3}{|l|}{ Esophageal } \\
\hline Chronic Non Specific Esophagitis & 8 & 1 \\
\hline Squamous cell Carcinoma & 272 & 33 \\
\hline $\begin{array}{l}\text { Normal mucosa with no specific pa- } \\
\text { thology }\end{array}$ & 4 & 0.5 \\
\hline Barret's oesophagus & 4 & 0.5 \\
\hline \multicolumn{3}{|l|}{ Oesophago-gastric junction } \\
\hline Squamous cell Carcinoma & 34 & 4 \\
\hline Adenocarcinoma & 50 & 6 \\
\hline \multicolumn{3}{|l|}{ Gastric } \\
\hline Chronic active gastritis & 120 & 15 \\
\hline Chronic nonspecific gastritis & 48 & 6 \\
\hline Gastric ulcer & 18 & 2 \\
\hline $\begin{array}{l}\text { Chronic gastritis with Intestinal meta- } \\
\text { plasia }\end{array}$ & 20 & 2 \\
\hline Chronic gastritis with dysplastic glands & 10 & 1 \\
\hline Chronic atrophic gastritis & 4 & 0.5 \\
\hline Hyperplastic polyp & 2 & 0.2 \\
\hline Granuloma & 2 & 0.2 \\
\hline Adenocarcinoma & 190 & 22 \\
\hline $\begin{array}{l}\text { Normal gastric mucosa with no specific } \\
\text { pathology }\end{array}$ & 30 & 4 \\
\hline \multicolumn{3}{|l|}{ Intestinal } \\
\hline No specific pathology & 2 & 0.2 \\
\hline Duodenal ulcer & 6 & 1 \\
\hline Non-specific duodenitis & 2 & 0.2 \\
\hline Villous atrophy & 2 & 0.2 \\
\hline Total & 828 & 100 \\
\hline
\end{tabular}

\section{DISCUSSION}

The typical site is the stomach, preceded by the oesophagus, for upper gastrointestinal endoscopic biopsy. The most frequent presenting symptom was dysphagia among patients with oesophageal malignancy. The most prominent signs of gastric malignancy have been dyspepsia and weight loss. ${ }^{12}$ Oesophageal and gastric cancers are the most common cancers found in men, according to the National Cancer Registry, while oesophageal cancer is ranked 3rd among women after breast \& cervix carcinoma. Most of the patients identified were male $(66 \%)$ and $40 \%$ were in the 4 th to 6 th decade of life. A similar finding was also observed by Shennak et $a l^{5}$ which they attributed to the greater degree of ex- 
posure of male subjects to different risk factors and greater attendance of male patients to the outpatient department of the hospital as compared to the female patients. Between the 40-60 age groups, a predominance of upper gastrointestinal tract diseases was observed, which showed a similar pattern to other studies published. The majority of oesophageal lesions have been described as malignant. ${ }^{13}$ These findings are comparable to research performed by Memon $\mathrm{F}$ et al. ${ }^{8}$ The bulk (54\%) of the cases involved gastric biopsies. Of the 444 cases, in line with other research, 180 cases of gastric malignancies were histopathologically diagnosed as gastric adenocarcinoma. While there is a comparatively lower incidence of gastric carcinoma in India than in other countries, there has been a high incidence in Southern India. As with other research, Antrum was the most common location for gastric carcinoma, followed by the body of the stomach. Chronic gastritis was the most common lesion among the non-neoplastic lesions (14\%), which is comparable to the study conducted by Khandige. ${ }^{14}$ Just 12 patients were diagnosed with a histopathological endoscopic biopsy involving the first two sections of the duodenum. Of these, six patients were diagnosed with duodenal ulcer, two with celiac disease, followed by two with non-specific duodenitis. ${ }^{14-17}$

\section{CONCLUSION}

Useful information is provided by biopsy sampling of the upper gastrointestinal mucosa during diagnostic endoscopy. In the present research, several non-neoplastic and neoplastic lesions have been identified across a wide spectrum of age $\&$ size distribution. The most common location for upper endoscopic biopsy in our sample was from the stomach, and it further indicates that the primary site of upper gastrointestinal malignancy is the oesophagus and the common histological form is squamous cell carcinoma. Owing to limited biopsy specimens, handling and processing items, weaknesses in diagnostic interpretation are sometimes encountered. However, to establish a definitive diagnosis, several bits of endoscopic biopsies from irregular looking mucosa are recommended. In addition to detecting upper gastrointestinal mucosal lesions at an early stage, endoscopic biopsies can detect changing trends in the spectrum of lesions, in particular atrophy, intestinal metaplasia and dysplasia, to avoid the progression of these lesions to invasive cancer. We, therefore, conclude that without biopsy, endoscopy is incomplete and hence the combination of both the techniques offers a strong diagnostic method for improved treatment of patients.

\section{ACKNOWLEDGEMENT}

The author acknowledges the immense help received from the scholars whose articles are cited and included in refer- ences to this manuscript. The author is also grateful to authors/editors/publishers of all those articles, journals and books from where the literature for this article has been reviewed and discussed.

\section{Conflict of Interest: Nil}

\section{Source of Funding: Nil}

\section{REFERENCES}

1. Black M. Endoscopic interpretation normal and pathologic appearance of the gastrointestinal tract. Raven Press New York 1984;1:13-15.

2. Karish R. A study on histopathologic spectrum of upper gastrointestinal tract endoscopic biopsies. Int J Med Res Health Sci 2013;2(3):418-424.

3. Suvakovic Z. Improving the detection rate of early gastric cancer requires more than open access gastroscopy: a five-year study. Gut 1997;41(3):308-313.

4. National Cancer Registry Programme. First All India Report 2001-2002. Vol 1. Indian Council of Medical Research. Bangalore, India. 2004.

5. Shennak M. Upper gastrointestinal diseases in symptomatic Jordanians: A prospective study. Ann Saudi Med 1997;17(4):471474.

6. Paymaster J. Cancer of the gastrointestinal tract in western India. Cancer 1968;21:279-287.

7. Khar H. Endoscopic and histopathological evaluation of 306 dyspeptic patients. Pak j Gastroenterol 2003;17:4-7.

8. Memon F. Upper gastro-intestinal endoscopic biopsy; the morphological spectrum of lesions. Profes Med J 2015;22(12):15741579.

9. Fuchs C. Gastric Carcinoma. New Engl J Med 1995;333(1):3236.

10. Kelley J. Gastric cancer: Epidemiology and risk factors. J Clin Epidemiol 2003;56:1-9.

11. Dicken B. Gastric Adenocarcinoma - Review and considerations for future directions. Annl Surg 2005;241(1):27-39.

12. Gajalakshmi V. An independent survey to assess the completeness of Registration: Population-based cancer registry, Chennai, India. Asian Pac J Cancer Prev 2001;2:179-183.

13. Marson B. Gastrointestinal pathology. 2nd edn, Black Well Scientific Publications, London, 1998:148-151.

14. Khandige S. The Conceding of Upper Gastro-intestinal Lesion Endoscopic Biopsy: A Bare Minimum for Diagnosis. Int J Sci Res 2015;4(2):264-266.

15. Fenoglio-Preiser C. Gastric carcinoma. In: WHO Classification of Tumours - Pathology and Genetics of Tumours of the Digestive System. Hamilton SR and Aaltonen LA (Eds), IARC Press: Lyon, France, 2000: 38-52.

16. Cherian J. Carcinoma of the oesophagus in Tamil Nadu (South India): 16-year trends from a tertiary centre. J Gastrointes Liver Dis 2007;16(3):245-249.

17. Abilash SC. Gastric carcinoma and Diagnosis. Sch J Appl Med Sci 2016;4(5E):1807-1813. 